\title{
Anatomical landmarks to locate the junction between transverse and sigmoid sinuses in translabyrinthine and retrosigmoid open surgical approaches
}

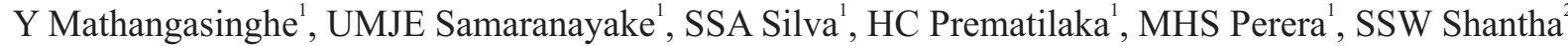

${ }^{1}$ Department of Anatomy, Faculty of Medicine, University of Colombo, Colombo, Sri Lanka

${ }^{2}$ Neville Fernando Teaching Hospital, Malabe, Sri Lanka

Keywords: Transverse sinus; sigmoid sinus; translabyrinthine approach; retrosigmoid approach; cerebellopontine angle

\section{Abstract}

\section{Introduction}

Hematoma due to dural-sinus damage is a known complication when introducing burr holes in open transcranial surgery. Our objective was to identify safe areas to avoid dural-sinus damage based on anatomical landmarks in translabyrinthine and retrosigmoid open surgical approaches where neuronavigation facilities are not available.

\section{Methods}

A descriptive anatomical study was conducted on adult skulls. Distances to transverse and sigmoid sinuses on either side were measured using fixed anatomical landmarks: asterion, inion, margins of suprameatal triangle and superior nuchal line. Measurements were standardized according to the cranial indices (cranial index=anteroposterior diameter/transverse diameter) of each skull.

\section{Results}

Thirty-two adult skulls (male:female=22:10) were studied. Mean cranial index, width of transverse and sigmoid sinuses were $0.785 \pm 0.045,9.1 \pm 2.3 \mathrm{~mm}$ and $9.7 \pm 1.2 \mathrm{~mm}$ respectively. Mean vertical distances from asterion and inion to the transverse sinus were $1.1 \pm 3.4 \mathrm{~mm}$ and $14.7 \pm 5.9 \mathrm{~mm}$ respectively. Posterior border of the sigmoid sinus was located $14.7 \pm 5.9 \mathrm{~mm}$, and $59.9 \pm 7.4 \mathrm{~mm}$ anterior to asterion and inion respectively. t-tests did not show significant differences of these distances on either sides $(p>.05)$. Pearson's correlations were insignificant between the measurements and the cranial indices $(p>.05)$. Measurements from the suprameatal triangle to the dural-sinuses had the minimum variance. In $>95 \%$ of the times the sigmoid sinus was located $\leq 23 \mathrm{~mm}$ posterior and $\leq 7 \mathrm{~mm}$ superior to the suprameatal triangle.

\footnotetext{
Correspondence: Yasith Mathangasinghe

E-mail: yasith@anat.cmb.ac.lk

Received: 19-06-2018 Accepted: 21-08-2018

(D) https://orcid.org/0000-0003-4641-5642

DOI: http://doi.org/10.4038/sljs.v36i2.8509
}

\section{Discussion and conclusions}

Suprameatal triangle was a consistent surface landmark to locate dural-sinuses. Dural-sinus damage could be avoided in $95 \%$ of the times by placing burr hole at least $7 \mathrm{~mm}$ superior and $23 \mathrm{~mm}$ posterior to the suprameatal triangle.

\section{Introduction}

Cerebellopontine angle (CPA) approach during neurosurgery is challenging (1). CPA is located posterior to the petrous part of temporal bone, anterior to the frontal part of cerebellum, superior to the arachnoid tissue of lower cranial nerves (1). CPA is a frequent site of neoplasms and vascular anomalies (2). The commonest pathology that requires surgical resection in this area is the CPA tumors, which has an incidence of $4 \%(2,3)$. Acoustic schwannomas are benign tumors accounting for approximately $80 \%$ of tumors of the CPA (4). This pathology requires surgical resection as the definitive treatment method (3-5).

The traditional method of CPA tumor removal is open surgery which involves placement of burr holes (6). The main advantage in open surgery is to have a good visualization of the surrounding structures (5). The common surgical methods in making the initial burr hole to reach the pathologies in the CPA are the subtemporal retrosigmoid $(7,8)$ and translabyrinthine approaches(9). Retrosigmoid approach involves cranial opening posterior to the sigmoid sinus preceded by retraction of the cerebellum to reach CPA (7). Translabyrinthine approach includes opening on to the CPA angle with external burr hole made in close proximity to transverse sinus and inner opening next to the sigmoid sinus (9). This method is only done when hearing preservation is not required (8). Transverse and sigmoid sinus junction will be closely related in translabyrinthine approach (9).

During the cranial drilling process and visualization, the surrounding neurovascular structures are prone to get damaged (10). Transverse sinus and sigmoid sinus are susceptible for injury leading to morbidity and mortality in patients during retrosigmoid and translabyrinthine craniotomy $(11,12)$. Neuronavigation is a novel neurosurgical adjunct used in operative management of brain pathologies (13). Localizing intracranial structures can be aided by preoperative image superimposition using stereotactic neuron- 
avigation techniques (14). Although the localization of these dural sinuses can be done using neuronavigation equipment; these advanced techniques are not readily available in all the centers around Sri Lanka. To prevent damage to these duralsinuses, surface landmarks can be used as a guide to recognize the transverse sigmoid sinus junction (12). Asterion, inion, superior nuchal line and suprameatal triangle were such structures believed to be helpful in locating the transverse sigmoid sinus junction $(15,16)$. However, during recent years cadaveric research on the location of these was found to be inconstant among individuals $(15,17)$.

In different populations the skull size and shape vary (18). There were a few studies done in the Western countries to locate the safe area in burr hole placement for CPA surgery (19). However, in Asia we could not find any articles addressing this issue. In this study we focused on finding a safe area of cranial entrance in initial burr hole making for CPA surgery, avoiding damage to the dural venous sinuses.

\section{Method}

A descriptive anatomical study was conducted on adult skulls obtained by self-donated cadavers in the Departments of Anatomy and Forensic Medicine, Faculty of Medicine, University of Colombo, Sri Lanka from March to June 2018. Both male and female adult skulls of Sri Lankan nationality were selected randomly. Skulls with deformities, trauma and previous surgeries were excluded from the study.

\section{Definitions}

The anatomical landmarks used in the present study were defined as below

- Inion - the most prominent point of external occipital protuberance (6)

- Nasion - the point on cranium where frontonasal and internasal sutures unite (6)

- Asterion- the junction of lambdoid, parieto-mastoid and occipito-mastoid sutures (6)

- Suprameatal triangle - a triangle formed by the posterior border of the external auditory canal, supramastoid crest and the vertical tangent to the posterior wall of the bony external auditory canal (6). The superior margin of the suprameatal triangle was taken as the reference point for all the vertically measured distances and the anterior margin was taken as the reference point for all the horizontally measured distances.

- Cranial index was calculated by dividing the maximum anteroposterior diameter of the skull by its maximum transverse diameter (6).

\section{Measurements}

All the measurements were recorded with the skull in the anatomical position in Frankfurt plane (6). The following measurements were obtained using a Vernier caliper [Manufacturer- Mitutoyo (Kanagawa- Japan) (Model No505-633-50)] and standard measuring tapes (Figure 1).

1. The horizontal distance from asterion to the posterior border of the sigmoid sinus

2. The vertical distance from asterion to the inferior border of the transverse sinus

3.The horizontal distance from the posterior border of suprameatal triangle to the anterior border of the sigmoid sinus

4.The vertical distance from the superior border of suprameatal triangle to the inferior border of the transverse sinus

5.The horizontal distance from the midpoint of nasion and inion to the posterior border of the sigmoid sinus

All the horizontal measurements towards the anterior aspect of the skull were considered positive and towards the posterior aspect were considered negative. All the vertical measurement towards the superior aspect of the skull was considered positive and towards the inferior aspect was considered negative. If any anatomical landmark used overlied the corresponding sinus, the distance was considered as zero.

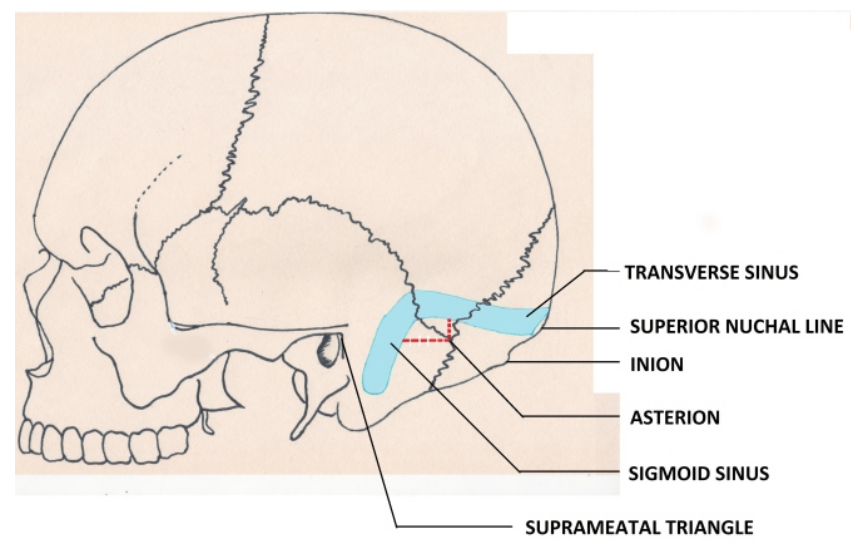

Figure 1. Diagrammatic representation of the anatomical landmarks used to locate the transverse and sigmoid sinuses. All the measurements were obtained with the skull positioned in Frankfurt plane. The horizontal and vertical distances measured from the asterion to the posterior border of the sigmoid sinus and the inferior border of the transverse sinus are marked in an interrupted line. 


\section{Statistical Analysis}

Standard descriptive analyses were conducted with a priori alpha of .05. Measurements were standardized according to the cranial indices of each skull. A safe zone was described for the transcranial burr hole placement using the measurements which had the least variation.

\section{Results}

Thirty-two adult skulls were studied. Of them, majority $(\mathrm{n}=22,68.7 \%)$ were male skulls. Mean cranial index was $0.785 \pm 0.045$. Mean width of transverse and sigmoid sinuses were $9.1 \pm 2.3 \mathrm{~mm}$ and $9.7 \pm 1.2 \mathrm{~mm}$ respectively. Mean vertical distances from asterion and inion to the transverse sinus were $1.1 \pm 3.4 \mathrm{~mm}$ and $14.7 \pm 5.9 \mathrm{~mm}$ respectively. Posterior border of the sigmoid sinus was located $14.7 \pm 5.9 \mathrm{~mm}$, and $59.9 \pm 7.4 \mathrm{~mm}$ anterior to asterion and inion respectively. The asterion (right side) was located on the transverse sinus in 10 (31\%) skulls, inferior to the transverse sinus in 6(19\%) skulls and superior to the transverse sinus in 16 (50\%) skulls. A summary of the measurements from standard anatomical landmarks to the respective sinuses are given in the Table 1. The distances were examined to determine the extent to which the assumption of normality was met. Shapiro-Wilk tests for each measurement ( $p>.05$ ) suggested that normality is a reasonable assumption. Independent sample t-tests were conduct to see if there is a significant difference of the above mentioned measurements on left and right sides of the skull. The results showed no significant differences of these distances on either sides ( $p>.05)$ (Table 1). Thus, measurements of left and right sides were pooled together in subsequent analyses. Independent sample t-tests did not show significant differences of any of these measurements between males and females ( $p>.05)$. Relationship between the cranial indices and the measurements were investigated using Pearson product-moment correlation coefficient. Preliminary analyses were performed to ensure no violations of the assumptions of linearity and homoscedasticity. No significant correlations were found between the two variables ( $p>.05)$. Results of the Pearson correlations are summarized in the Table 1. Interquartile ranges of each measurement are summarized in a boxplot in Figure 2. Minimum variances were noted in the measurements from the suprameatal triangle to transverse sinus (8.6), asterion to transverse sinus (11.8) and suprameatal triangle to sigmoid sinus (13.8). In $>95 \%$ of the times the sigmoid sinus was located $\leq 70.0 \mathrm{~mm}$ anterior to the inion, $\leq 25 \mathrm{~mm}$ anterior to the asterion and $\leq 23$ $\mathrm{mm}$ posterior to the posterior border of the suprameatal triangle. The transverse sinus was located $\leq 16 \mathrm{~mm}$ inferior to the superior nuchal line, $\leq 9 \mathrm{~mm}$ superior to the asterion and $\leq 7 \mathrm{~mm}$ superior to the superior margin of the suprameatal triangle (supramastoid crest).

Table 1. A summary of measurements to the transverse and sigmoid sinuses from fixed anatomical landmarks and the results of an independent sample t-test comparing the distances on left and right sides of the skulls (For a detailed description of measurements, please refer to the relevant section in methods). SD - Standard Deviation; Sig - Significance level; SS - Sigmoid Sinus; t- result (tvalue) of the independent sample t-test; TS - Transverse Sinus.

\begin{tabular}{|c|c|c|c|c|c|c|c|c|c|c|c|c|c|c|}
\hline \multirow[t]{2}{*}{ Measure nent } & \multicolumn{3}{|c|}{ Mean $(\mathrm{mm})$} & \multicolumn{3}{|c|}{$\mathrm{SD}(\mathrm{mm})$} & \multicolumn{2}{|c|}{ Range (mm) } & \multicolumn{2}{|c|}{$\begin{array}{c}\text { No. of } \\
\text { measurements } \\
\text { superimposed } \\
\text { on a sinus }\end{array}$} & \multicolumn{2}{|c|}{ Results of t-test } & \multicolumn{2}{|c|}{$\begin{array}{c}\text { Results of Pearson } \\
\text { Bivariate Pearson's } \\
\text { correlations }\end{array}$} \\
\hline & $R$ & $\bar{L}$ & $\mathrm{~B} / \mathrm{L}$ & $\bar{R}$ & L & $\mathrm{B} / \mathrm{L}$ & $\bar{R}$ & $\mathrm{~L}$ & $R$ & $\mathrm{~L}$ & t Value & $\begin{array}{l}\text { Signifi } \\
\text { cance }\end{array}$ & $\begin{array}{l}\text { Pearson } \\
\text { correlation } \\
\text { coefficient } \\
\{r \mid \\
\end{array}$ & $\begin{array}{l}\text { Signific } \\
\text { ance }\end{array}$ \\
\hline Asterion to TS & 1.3 & 0.8 & 1.1 & 2.8 & 4.0 & 3.4 & $\begin{array}{l}-4.0 \text { to } \\
+11.0\end{array}$ & $\begin{array}{l}-7.0 \text { to } \\
+11.0\end{array}$ & 10 & 10 & 0.543 & 0.589 & -0.129 & 0.309 \\
\hline Asterion to SS & 14.9 & 14.5 & 14.7 & 6.5 & 5.5 & 6.0 & $\begin{array}{l}+1.0 \text { to } \\
+30.0\end{array}$ & $\begin{array}{l}+3.0 \text { to } \\
+25.0\end{array}$ & 0 & 0 & 0.251 & 0.803 & 0.075 & 0.555 \\
\hline $\begin{array}{l}\text { Superior nuchal } \\
\text { line to TS }\end{array}$ & 2.4 & 2.2 & 2.3 & 6.4 & 7.0 & 6.6 & $\begin{array}{l}-15.0 \text { to } \\
+18.0\end{array}$ & $\begin{array}{l}-19.0 \text { to } \\
+18.0\end{array}$ & 6 & 7 & 0.131 & 0.896 & 0.005 & 0.971 \\
\hline Inion to SS & 59.7 & 60.0 & 60.0 & 7.9 & 7.0 & 7.4 & $\begin{array}{l}+45.0 \text { to } \\
+85.0\end{array}$ & $\begin{array}{l}+41.0 \text { to } \\
+73.0\end{array}$ & 0 & 0 & -0.168 & 0.867 & 0.080 & 0.530 \\
\hline $\begin{array}{l}\text { Suprameatal } \\
\text { triangle to TS }\end{array}$ & 1.9 & 1.0 & 1.5 & 2.9 & 3.0 & 2.9 & $\begin{array}{l}-3.0 \text { to } \\
+9.0\end{array}$ & $\begin{array}{l}-5.0 \text { to } \\
+7.0\end{array}$ & 17 & 9 & 1.195 & 0.237 & 0.004 & 0.975 \\
\hline $\begin{array}{l}\text { Suprameatal } \\
\text { triangle to SS }\end{array}$ & -18.0 & -18.3 & 18.2 & 3.7 & 3.8 & 3.7 & $\begin{array}{l}-10.0 \text { to } \\
-261.0\end{array}$ & $\begin{array}{l}-9.0 \text { to }- \\
23.0\end{array}$ & 0 & 0 & -0.334 & 0.739 & 0.064 & 0.615 \\
\hline Width of TS & 9.2 & 9.0 & 9.1 & 2.2 & 2.5 & 2.3 & $\begin{array}{l}+4.0 \text { to } \\
+15.0\end{array}$ & $\begin{array}{l}+5.0 \text { to } \\
+15.0\end{array}$ & 0 & 0 & 0.265 & 0.792 & 0.101 & 0.429 \\
\hline Width of SS & 9.9 & 9.6 & 9.7 & 1.3 & 1.1 & 1.2 & $\begin{array}{l}+7.0 \text { to } \\
+12.0\end{array}$ & $\begin{array}{l}+7.0 \text { to } \\
+12.0\end{array}$ & 0 & 0 & 0.908 & 0.368 & -0.080 & 0.529 \\
\hline
\end{tabular}




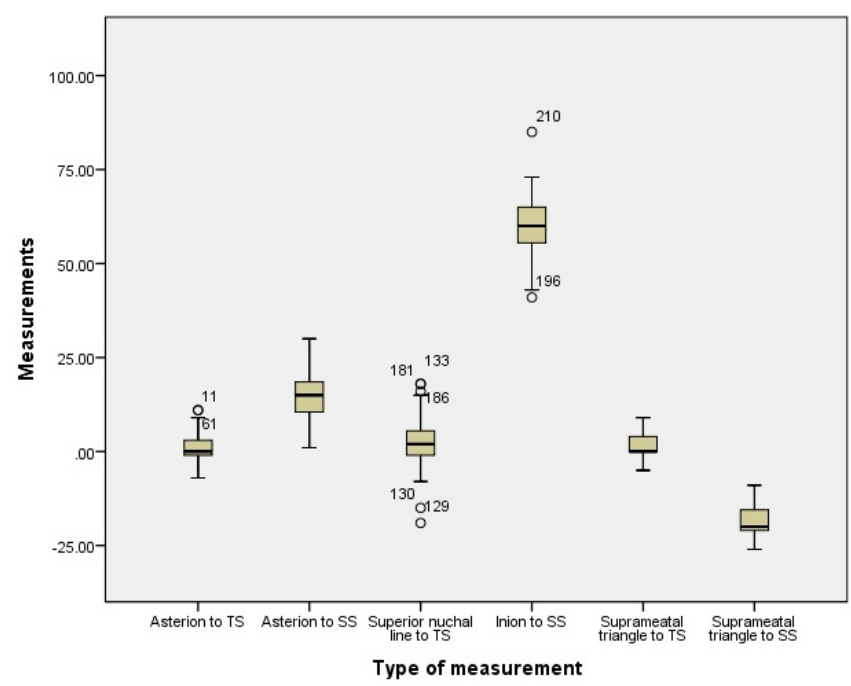

Figure 2. A boxplot of corresponding vertical and horizontal distances from the anatomical landmarks to the transverse and sigmoid sinuses. All the horizontal measurements towards the anterior aspect of the skull were considered positive and towards the posterior aspect were considered negative. All the vertical measurement towards the superior aspect of the skull was considered positive and towards the inferior aspect was considered negative. If any anatomical landmark used overlies the corresponding sinus, the distance was considered as zero. Measurements are given in millimeters.

\section{Discussion}

Anatomical structures asterion, inion, superior nuchal line and suprameatal triangle were used as landmarks to locate the junction between transverse and sigmoid sinuses $(15,16)$. However, further studies revealed that there were inconsistencies with the transverse and sigmoid junction and the location of these anatomical structures $(15,17)$. Also, asterion was difficult to locate intra-operatively (19). Retrosigmoid and translabyrinthine approaches are main methods used to gain access in the CPA tumor resection $(7,8)$. They were first described by Cushing, followed by further adjustments and alterations by Seiffert and Dandy among others, in order to gain entrance to the CPA (20). During this procedure with no advanced neuronavigation techniques available, the transverse and sigmoid sinus damage can cause minor injuries to major life threatening ones (11). Thus, when gaining entrance to the cranial cavity it is mandatory to have an idea of the location of tranverse and sigmoid dural venous sinuses.

A study done on 100 patients undergoing computed tomography angiography showed that the asterion was directly above the transverse and sigmoid sinus junction in $81 \%$, superior to it in $4 \%$ and inferior to the junction in $15 \%$ (20). Another cadaveric study on 24 specimens indicated the asterion to be located over the transverse sinus in all the specimens (21). But in the same study, the asterion could not be identified clearly in 14 sides (21). The mean vertical distance from asterion to the transverse sinus was $1.1 \pm 3.4 \mathrm{~mm}$ in our study. Asterion was located on the right transverse sinus in $31 \%$, inferior to the transverse sinus in $26 \%$ and superior to the transverse sinus in $42 \%$. Distance from inion to the duralsinuses was not described in any of the former studies. However, length from an arbitrary midline structure was used in one study to measure the length to asterion (21). Ucerler and Govsa reported; asterion to the root of zygoma was 54.1 \pm $5.42 \mathrm{~mm}$ on the right side and $55 \pm 5.4 \mathrm{~mm}$ on the left side (22). Avci, et al. stated the distance from the asterion to the zygomatic root in the cadavers ranged between $45.9 \mathrm{~mm}$ to 69 $\mathrm{mm}$ (21). In our study the sigmoid sinus was located 14.7 \pm 5.9 $\mathrm{mm}$ and $59.9 \pm 7.4 \mathrm{~mm}$ anterior to asterion and inion respectively. Sheng, et al. concluded that superior nuchal line failed to make a striking impression in locating the transverse sinus (23). The findings of our study are comparable with this.

The suprameatal triangle was used as a landmark to locate the junction between transverse and sigmoid sinuses (24). Nevertheless, there were no anatomical studies indicating any distance from suprameatal triangle to the transverse or sigmoid sinus. In our study, the transverse sinus was situated superiorly at a mean vertical distance of $1.5 \pm 2.9 \mathrm{~mm}$ and the sigmoid sinus was located posteriorly at a mean horizontal distance of $18.2 \pm 3.7 \mathrm{~mm}$ with reference to the corresponding margins of the suprameatal triangle. The location of the dural venous sinuses with reference to the suprameatal triangle had the minimum variance. Thus, it is a promising anatomical landmark which can be used in the retrosigmoid approach to the CPA.

Only a few studies were conducted in localizing the safe area for surgical access. Tubbs et al. established that the cranial entrance should be in made $9.1 \mathrm{~mm}$ and $9.8 \mathrm{~mm}$ from the mastoid line (19). Right side burr hole to be made inferior to the left, because of the width and dominance of right transverse sinus (19). Bozbuga, et al. after doing a study on 84 adult skulls said the ideal burr hole placement is below the superior nuchal line and posterior to the mastoid tip and squamo-parietal suture junction (7). Nevertheless, the distances to the safe cranial entrance was not defined in both of these studies. Avici, et al. mentioned that the superior burr hole to be placed $1 \mathrm{~cm}$ below the superior nuchal line $1 \mathrm{~cm}$ medial to the mastoid groove (21). However, the conclusion was based after studying only 10 skulls.

Anatomical land marks to transverse and sigmoid sinuses were not measured in an Asian population before. Large scale studies are necessary for the accurate population inferences. The differences of the measurements in our study could be due to morphological variations of the skulls in sample populations. Thus, it is necessary to conduct similar anatomical studies in different ethnicities and populations. 


\section{Conclusion}

We observed discrepancies of the described anatomical landmarks related to the burr hole placement in CPA tumor resection that avoids damage to the transverse and sigmoid sinuses. Since the advanced neuronavigation equipments are not readily available throughout the country, it is beneficial to have an idea of such landmarks in dural sinus location. Suprameatal triangle was a consistent surface landmark with a minimum variance. Dural sinus damage could be avoided in $95 \%$ of the times by making the initial burr hole at least $7 \mathrm{~mm}$ superior to the superior margin of the suprameatal triangle (supramastoid crest) and $23 \mathrm{~mm}$ posterior to the posterior margin of the suprameatal triangle. However, large scale studies in different ethnicities with clinical and imaging correlations are necessary to confirm these anatomical landmarks.

All authors disclose no conflict of interest. The study was conducted in accordance with the ethical standards of the relevant institutional or national ethics committee and the Helsinki Declaration of 1975, as revised in 2000 .

\section{References}

1. Chaynes P, Deguine O, Moscovici J, Fraysse B, Bécue J, Lazorthes Y. Endoscopic anatomy of the cerebellopontine angle: a study in cadaver brains. Neurosurgical focus. 1998;5(3):E13. https://doi.org/10.3171/foc.1998.5.3.14

2. Mirza S, Malik T, Ahmed A, Willatt D, Hughes D. Incidental findings on magnetic resonance imaging screening for cerebellopontine angle tumours. The Journal of Laryngology \& Otology. 2000;114(10):750-4. https://doi.org/10.1258/0022215001904077

3. Van Rompaey J, Bush C, McKinnon B, Solares AC. Minimally invasive access to the posterior cranial fossa: an anatomical study comparing a retrosigmoidal endoscopic approach to a microscopic approach. Journal of Neurological Surgery Part A: Central European Neurosurgery. 2013;74(01):001-6. https://doi.org/10.1055/s-0032-1330119

4.Anderson TD, Loevner LA, Bigelow DC, Mirza N. Prevalence of unsuspected acoustic neuroma found by magnetic resonance imaging. Otolaryngology-Head and Neck Surgery. 2000;122(5):643-6.

https://doi.org/10.1016/S0194-5998(00)70189-6

5. Memari F, Hassannia F, Abtahi SHR. Surgical outcomes of cerebellopontine angle tumors in 50 cases. Iranian journal of otorhinolaryngology. 2015;27(78):29.

6. Keith L. Moore AFD, Anne M.R. Agur. Moore Clinically oriented anatomy. 7 ed: Woters Kluwer; 2014. 828-30 p.

7. Bozbuga M, Boran BO, Sahinoglu K. Surface anatomy of the posterolateral cranium regarding the localization of the initial burr-hole for a retrosigmoid approach. Neurosurgical review. 2006;29(1):61-3. https://doi.org/10.1007/s10143-005-0417-2

8. Elhammady MS, Telischi FF, Morcos JJ. Retrosigmoid Approach:: Indications, Techniques, and Results. Otolaryngologic Clinics of North America. 2012;45(2):375-97.

https://doi.org/10.1016/j.otc.2012.02.001

9. Arriaga MA, Lin J. Translabyrinthine Approach:: Indications, Techniques, and Results. Otolaryngologic Clinics of North America. 2012;45(2):399-415.

https://doi.org/10.1016/j.otc.2011.12.009
10. Cappabianca P CM, Esposito F, de Divitiis E, Tschabitscher M. Endoscopic examination of the cerebellar pontine ange. Clinica neurology and neurosurgery. 2002 Sep 1;104(4):387-91.

https://doi.org/10.1016/S0303-8467(02)00022-7

11. Oh GS, Arnone GD, Abou-Al-Shaar H, Barks AL, Wong A, Charbel FT. Surgical Repair of Iatrogenic Transverse-Sigmoid Sinus Laceration with a Dural Flap During Skull Base Tumor Surgery: A Technical Case Report. World neurosurgery. 2017;106:1050. e7-. e10.

12. da Silva EB, Leal AG, Milano JB, da Silva LFM, Clemente RS, Ramina R. Image-guided surgical planning using anatomical landmarks in the retrosigmoid approach. Acta neurochirurgica. 2010;152(5):905-10.

https://doi.org/10.1007/s00701-009-0553-5

13. Orringer DA, Golby A, Jolesz F. Neuronavigation in the surgical management of brain tumors: current and future trends. Expert review of medical devices. 2012;9(5):491-500.

https://doi.org/10.1586/erd.12.42

14. Cheon J-E. Intraoperative neurosonography revisited: effective neuronavigation in pediatric neurosurgery. Ultrasonography. 2015;34(2):79. https://doi.org/10.14366/usg.14054

15. Gharabaghi A, Rosahl S, Feigl G, Samii A, Liebig T, Heckl S, et al. Surgical planning for retrosigmoid craniotomies improved by 3D computed tomography venography. European Journal of Surgical Oncology. 2008;34(2):227-31.

https://doi.org/10.1016/j.ejso.2007.01.032

16. Chanda A, Nanda A. Retrosigmoid intradural suprameatal approach: advantages and disadvantages from an anatomical perspective. Operative Neurosurgery. 2006;59(suppl_1):ONS-1ONS-6.

17. Wang C, HAN G, You C, Liu C. Clinical Application of Scalp Markers and Three-Dimensional Sliced Computed Tomography Reconstructions of the Skull Transverse-Sigmoid Sinus Groove in the Retrosigmoid Approach. Turk Neurosurg. 2017:1.

18. Looker AC, Melton LJ, Harris T, Borrud L, Shepherd J, McGowan J. Age, gender, and race/ethnic differences in total body and subregional bone density. Osteoporosis international. 2009;20(7):1141-9. https://doi.org/10.1007/s00198-008-0809-6

19. Tubbs RS, Loukas M, Shoja MM, Bellew MP, Cohen-Gadol AA. Surface landmarks for the junction between the transverse and sigmoid sinuses: application of the "strategic" burr hole for suboccipital craniotomy. Operative Neurosurgery. 2009;65(suppl_6):ons37-ons41.

20. Tatagiba M, Acioly MA. Retrosigmoid approach to the posterior and middle fossa. Samii's Essentials in Neurosurgery: Springer; 2014.p. 217-35.

21. Avci E, Kocaogullar Y, Fossett D, Caputy A. Lateral posterior fossa venous sinus relationships to surface landmarks. Surgical neurology. 2003;59(5):392-7.

https://doi.org/10.1016/S0090-3019(03)00037-5

22. Ucerler H, Govsa F. Asterion as a surgical landmark for lateral cranial base approaches. Journal of cranio-maxillo-facial surgery. 2006;34(7):415-20. https://doi.org/10.1016/j.jcms.2006.05.003

23. Sheng B, Lv F, Xiao Z, Ouyang Y, Lv F, Deng J, et al. Anatomical relationship between cranial surface landmarks and venous sinus in posterior cranial fossa using CT angiography. Surgical and radiologic anatomy. 2012;34(8):701-8.

https://doi.org/10.1007/s00276-011-0916-5

24. Ebner F, Koerbel A, Kirschniak A, Roser F, Kaminsky J, Tatagiba M. Endoscope-assisted retrosigmoid intradural suprameatal approach to the middle fossa: anatomical and surgical considerations. European journal of surgical oncology. 2007;33(1):109-13.

https://doi.org/10.1016/j.ejso.2006.09.036 